\title{
Non-invasive Morphological and Elemental Analysis of Ivory Plate for Artworks Authentication Using ESEM and EDS
}

\author{
Eva Tihlař́ková ${ }^{1}$, Vilém Neděla ${ }^{1}$ Janka Hradilová $^{2}$ and David Hradil Hi, $^{2,3}$ \\ 1. Environmental Electron Microscopy Group, Institute of Scientific Instruments of the CAS, Brno, \\ Czech Republic \\ 2. Academy of Fine Arts in Prague, ALMA laboratory, Prague, Czech Republic \\ 3. Institute of Inorganic Chemistry of the CAS, ALMA laboratory, Řež, Czech Republic
}

In a market that is flooded with forgeries, the first step in determining the value is identification of the artwork authenticity. Also from the art history point of view professional expertise based on different techniques are necessary. In this work we introduce Environmental scanning electron microscopy (ESEM) with energy-dispersive X-ray spectroscope analysis (EDS) as non-invasive methods for micromorphological and elemental analysis of ivory samples used as supports for historical miniature painting. Miniature portraits are very subtle paintings, where any collection of micro-samples is generally unacceptable. Their popularity was mainly in the 19th century, but there are a number of copies and imitations, whose recognition is difficult. The true natural ivory was widely substituted by different bones or an artificial ivory, represented by various types of plastics.

From anatomical point of view, genuine animal ivory is an upper incisor consisted mainly from dentin and in upper part from thin layer of email. Dentine is interlaced with sub-parallel channels named dental tubules. Dentine is consisted from hydroxyapatite $\left(\mathrm{Ca}_{5}\left(\mathrm{PO}_{4}\right)_{3}(\mathrm{OH})\right)$, however a tissue is created from organic part $(30 \%)$ and minerals $70 \%[1,2]$.

From historical point of view, the composition and surface morphology of ivory supports as well as the composition of paint layers is conducted to identify the artworks specifics such as region and date of creation, and the painting technique used, which is specific to each artist. In the case of miniature painting only non-invasive approaches of the analysis should be carried out. These nonconductive samples could be very susceptible to environmental and electron beam conditions [3]. ESEM is suitable method allowing using optimal environmental humidity to protect sample drying, cracking or potential chemical modification.

As the first task pure ivory plate without any painting was studied with the aim to confirm its natural origin and to optimize conditions of safe measurement of valuable artworks on this type of support. This plate was probably made in the early 20th century and was designed to produce a forgery.

Whole elliptical plate with the dimensions of $50 \mathrm{~mm}$ in length was studied using ESEM QUANTA 650 FEG equipped with MAPS software for imaging of large area. Elemental analysis and mapping were realized with EDS Bruker XFlash 6/60. Working conditions and detectors were selected according to the method. For morphological study: from 200 to $400 \mathrm{~Pa}$ of water vapour, beam energy $10 \mathrm{kV}$, probe current $50 \mathrm{pA}$, working distance $8 \mathrm{~mm}$ and GSED (FEI) detector were used. Mapping and elemental analysis were made under conditions: $150 \mathrm{~Pa}$ of water vapour, beam energy $15 \mathrm{kV}$ and probe current $70 \mathrm{pA}$, working distance $10 \mathrm{~mm}$. A GAD (FEI) detector was used for imaging and shortening the gas path length.

Our observation confirmed the authenticity of the plate. The characteristic dentine tubules are visible on the Fig. $1 \mathrm{~B}$ and D (black arrows). Micrographs on Fig. 1A, B show the presence of many scrapes 
caused due to support roughening. The roughening of the surface was a necessary step of preparation prior to application of the paint.

Elemental analysis also proved the substrate authenticity. Presence of hydroxyapatite with minerals as magnesium and sodium are visible in spectrum in Fig. 1C. Presence of approx. 5\% $\mathrm{MgO}$ is characteristic chemical feature for ivory, magnesium concentration in bone and antler is below the detection limit [4]. Magnesium is mainly accumulated in dental tubules or creates concentrated structures well visible in elemental image in Fig. 1D.

Our results show well suitability of the ESEM for analysis of small historical artworks. Non-invasive observation in suitable environmental conditions can be adjusted according to a need of concrete samples. ESEM also meet the requirements of no treatment or surface coating with conductive layers of the highly valuable samples. Moreover, positive ions minimizing sample contamination. It is important especially in large area imaging where the unacceptable color changing is prevented [5].

\section{References:}

[1] R L Lyman, in "Vertebrate Taphonomy" (Cambridge University Press, Cambridge), p. 79.

[2] M Locke, Bone, Ivory and Horn Identifying Natural Materials (Schiffer Publishing 2013)

[3] V Neděla et al, Microscopy and Microanalysis 21(3) (2015), p. 1697.

[4] M Christensen, Technologie de l'ivore au paléolithique supérieur. (BAR International Series number 751, 1999).

[5] The authors acknowledge funding from the NPUI LO1417 and LO1212 together with the European Commission (ALISI No. CZ.1.05/2.1.00/01.0017) and Czech Science Foundation (17-25687S).

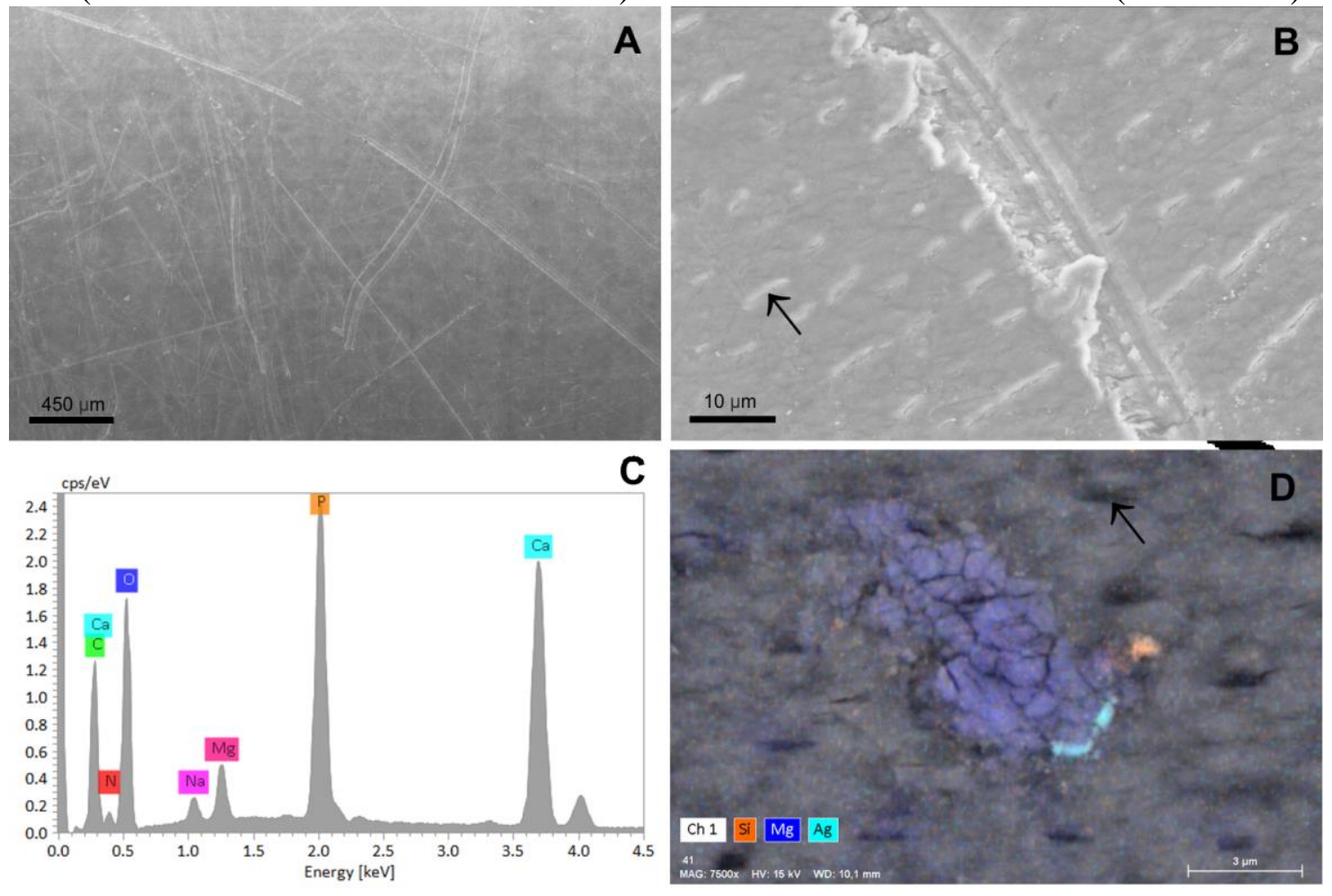

Figure 1. A) Topography of the ivory surface with detail of scrap B). C) Results of elemental analysis proving the presence of hydroxyapatite and D) EDS mapping of impurity on the surface. Dental tubules are highlighted by white arrows. 